\title{
Genetic Determinants of Pediatric HIV-1 Infection: Vertical Transmission and Disease Progression Among Children
}

\author{
Claudine Matte ${ }^{1,2}$ and Michel Roger ${ }^{1,2}$ \\ ${ }^{1}$ Laboratoire d'immunogénétique, Centre de Recherche du Centre Hospitalier de l'Université de Montréal \\ (CHUM), Montréal, Canada \\ ${ }^{2}$ Département de microbiologie et immunologie de l'Université de Montréal, Montréal, Canada \\ Accepted July 3, 2001
}

\begin{abstract}
It is very likely that perinatal human immunodeficiency virus type 1 (HIV-1) infection is influenced by a combination of virologic and host factors. A greater understanding of the role played by various risk factors for HIV- 1 infection is crucial for the design of new preventive and therapeutic strategies. In recent years, a number of studies have suggested that host genetic factors are important determinants of both the susceptibility to perinatal HIV-1 infection and the subsequent pathogenesis of acquired immunodeficiency syndrome (AIDS). Control of HIV-1 infection involves the processing of specific viral peptides and their presentation to cells of the immune system by highly polymorphic human leukocyte antigen (HLA) alleles. The contribution of
\end{abstract}

multiple HLA class I and II alleles in modulating pediatric HIV/AIDS outcomes has now been confirmed by several independent groups. Penetration of HIV-1 into cells is mediated by interaction between CD4 and chemokine receptors that serve as entry coreceptors. Genetic polymorphisms in chemokine ligand and chemokine receptor genes have recently been associated both with mother-to-child HIV-1 transmission and disease progression in children. These observations suggest a key role for genetic factors in pediatric HIV-1 infection. This article describes the current state of knowledge regarding host genetic influences on pediatric HIV-1 infection and discusses the role of these genes in HIV/AIDS pathogenesis.

\section{Introduction}

Globally, UNAIDS and the World Health Organization (WHO) estimated that 15.7 million women, most of whom are of childbearing age, were living with human immunodeficiency virus (HIV) at the end of 1999 (1). With an estimated 1.5 million HIV-positive women becoming pregnant each year, almost 600,000 children will be infected by mother-to-child transmission (MTCT) annually. Over 3.8 million children have died of AIDS since the beginning of the epidemic. Infant mortality rates in east and southern Africa are currently $33-66 \%$ higher than they would be without AIDS. Many of the gains in infant mortality and life expectancy made by postcolonial African governments have been completely reversed. As a consequence of this large decline in human resources, the very future of Africa is threatened (2). Thus, perinatal HIV-1 infection constitutes a significant global health

Address correspondence and reprint requests to: Dr. Michel Roger, Département de microbiologie, Hôpital Notre-Dame du CHUM, 1560 Sherbrooke Est, Montréal, Québec, Canada H2L 4M1. Phone: (514) 890-8000 ext. 2-5802; fax: (514) 412-7512. problem and the prevention of transmission is a high public health priority. A greater understanding of the role played by various risk factors for HIV-1 infection is crucial for the design of new preventive and therapeutic strategies.

Although, vertical transmission of HIV-1 has been correlated with a wide range of viral, maternal, obstetrical, and behavioral factors (reviewed in 3-6), the exact factors that influence the transmission of HIV-1 from a mother to her child remain to be identified. In children with perinatally acquired HIV-1 infection, the expression of clinical and immunologic signs of disease appear to follow a bimodal distribution (7). Approximately $15-20 \%$ of infected infants have an early and severe course of disease and die within the first 2 years of life. The remaining children progress more slowly and have a less severe course, surviving an average of 8 years or more. Several factors have been suggested to influence disease progression in children infected with HIV (reviewed in 6,8,9). There is a broad consensus that intrauterine infection $(10,11)$, high viral load at birth $(12,13)$, and the viral phenotype $(14,15)$ are all major risk factors influencing disease progression in HIV-1-infected children. 
Table 1. Genetic factors affecting vertical transmission of HIV-1

\begin{tabular}{llc}
\hline Factor & \multicolumn{1}{c}{ Effect } & Reference \\
\hline HLA & & \\
HLA-A2 & Protection & 30 \\
HLA-A3-B7-DR2 & Protection & 17,18 \\
HLA-Al-B8-DR3 & Higher risk & 17,18 \\
HLA-DQB1*0604 & Higher risk & 19 \\
HLA-DR13 & Protection & 18 \\
(DRB1*1301,*1302, $\left.{ }^{*} 1303\right)$ & & \\
Chemokine receptors & & \\
CCR5- $\Delta 32^{a}$ & Protection & 20 \\
CCR5-59356-T & Higher risk & 21 \\
SDF1-3'A & Higher risk & 22 \\
& & \\
\hline
\end{tabular}

${ }^{a}$ See Table 3 for more details on CCR5- $\Delta 32$ and risk of MTCT.

A growing body of evidence suggests that host genetic factors are important determinants of both the susceptibility to perinatal HIV-1 infection and the subsequent pathogenesis of AIDS (Tables 1 and 2). To date, work in this area has focused on genes in two systems critical to the immune response: the family of molecules that mediate antigen presentation and the chemokine ligands and receptors that have recently been identified as cofactors for HIV-1 cell entry. Accordingly, this review will focus on the role of human leukocyte antigen (HLA), chemokine receptors, and stromal-derived factor-1 (SDF1) genes on perinatal HIV-1 transmission and disease progression to AIDS.

\section{HLA and Effector Cells of the Immune System}

Genes in the HLA region are grouped in two major classes: class I (A, B, C, E, F, G) and class II (DM, DP, DQ, DR). Products of HLA genes mediate intracellular antigen processing, transport across cell compartments, and cell-surface presentation of antigenic peptides to lymphocytes (16). HLA is the most highly polymorphic biologic system known to exist in humans. The extensive polymorphism of HLA results in a broad diversity of potential immune responses against HIV-1 and other pathogens in human populations (29). This fact is consistent with observations that individuals with certain HLA types may be more susceptible or resistant to HIV-1 infection. Kilpatrick et al. (17), in a serologic HLA typing study of Scottish infants, observed that the HLA-A3-B7-DR2 haplotype was associated with protection against HIV-l infection whereas the HLA-A1-B8-DR3 haplotype was increased in frequency among HIV-infected children. These findings were subsequently confirmed by another group using molecular HLA typing methods. In that study, the HLA-DR2 allele (DRB1*1501) was associated with seroreversion while the HLA-DR3 $\left(\mathrm{DRB1}{ }^{*} 03011\right)$ allele was positively associated with the occurrence of HIV-1 infection among white American infants (18). Interestingly, the DRB $1^{*} 03011$ allele associations differed sharply between ethnic groups. In black Americans, this allele was significantly associated with a diminution in vertically transmitted HIV-1 infection. Moreover, several HLADR13 alleles $\left(\mathrm{DRB1}^{*} 1301,{ }^{*} 1302,{ }^{*} 1303\right)$ were associated with protection against HIV-1 transmission among black infants but not in white children. In a recent study, the presence of HLA-A2 was associated with a 9-fold reduction in the risk of perinatal HIV infection in an East African population (30).

Specific HLA alleles have also been associated with pediatric HIV disease progression. The HLA DR3 haplotype (DRBI*0301-DQA*0501-DQB1*0201) appears to be associated with increased incidence of encephalopathy, faster rate of CD4 cell decline, and death before 2 years of age in African-American children (19) and with the development of severe clinical manifestations in Spanish children (24). Survival of children in these same studies to at least 2 years of

Table 2. Genetic factors implicated in HIV-1 disease progression among children

\begin{tabular}{|c|c|c|}
\hline Factor & Effect & Reference \\
\hline \multicolumn{3}{|l|}{ HLA } \\
\hline HLA-A*2301 & Rapid progression & 23 \\
\hline HLA-DPB 1*0101 & Survival & 19 \\
\hline HLA-DPB $1 * 0301$ & Slow progression & 24 \\
\hline HLA-DR3 (DRB 1*0301-DQA*0501-DQB 1*0201) & Rapid progression & 19,24 \\
\hline HLA-DR $13(* 1301, * 1302, * 1303, * 1310)$ & Survival & 23 \\
\hline \multicolumn{3}{|l|}{ Chemokine receptors } \\
\hline CCR $5-\Delta 32^{a}$ & Slow progression & $25-27$ \\
\hline CCR2-64I & Slow progression & 28 \\
\hline
\end{tabular}

${ }^{a}$ See Table 3 for more details on CCR5- 32 and rate of HIV disease progression. 
age and decreased risk of clinical manifestations were associated with HLA DPB1 alleles (DPB1*0101, ${ }^{*} 0301$ ). In a mixed American population, Chen et al. (23) found a strong relationship between rapid disease progression in children and presence of the HLA-A $* 2301$ allele while HLA DR 13 alleles were associated with long-term survival in infected children.

Taken together, these data suggest that the HLA DR3 haplotype is associated with both increased risks of vertical transmission of HIV-1 and pediatric disease progression, while the HLA DR 13 and HLA DPB 1 alleles are associated with protection against HIV-1 infection. Numerous studies have already associated the HLA-DR3 haplotype with faster AIDS progression in HIV-seropositive adults (reviewed in 31). However, there is a discordant effect of the HLA DR3 (DRB 1*03011) and HLA-A2 alleles in the black and white ethnic groups. Seemingly inconsistent results across ethnic groups may reflect the genetic heterogeneity of HLA. In fact, the full extent of HLA polymorphism is not distributed randomly in the general population. Rather, ethnic and geographic clustering of HLA types occurs, owing in part to the unique biologic histories of subpopulations that have shaped the distribution of HLA alleles over time (e.g., exposure to infectious agents).

Class I-restricted cytotoxic T lymphocytes (CTLs) exert significant immune pressure on HIV-1, suggesting that this response might participate in modulating transmission and disease progression. There is an inverse correlation between plasma RNA viral load and HIV-specific CTL frequencies in patients with HIV-1 infection (32). The impact of CTL responses in HIV-infected pregnant women on vertical transmission has been recently investigated. CTL precursor frequencies specific for pol and nef HIV variants were higher during pregnancy in nontransmitting than in transmitting mothers (33). Because $n e f$ represents an early transcript during the replication of HIV, a strong nef-specific CTL response may be important for the clearance of HIV soon after protein expression and the control of further viral dissemination. Interestingly, a nef-specific CTL response has also been observed in uninfected children born to HIV-positive women (34). A study by Wilson et al. (35) demonstrated that amino acid substitutions within the targeted CTL epitopes and immune escape from CTL recognition are associated with transmitting mothers. However, the transmitted virus can be a CTL-susceptible form, suggesting inadequate in vivo immune control. Although the CTL response is an important mediator of protective immunity and has been implicated in controlling virus load, the maternal CTL response is insufficient to determine the fate of HIV vertical transmission.

Because HIV-1 is known to infect cells within the placenta $(36,37)$, the increased frequency of chorioamnionitis in mothers with AIDS could potentially result in an increased exchange of maternal and fetal cells. These observations suggest that the probability of in utero exposure to free virus or to maternal HIV-infected cells is likely to be very high. However, only a minority of children is ultimately infected by their mothers. It has been proposed that fetal alloimmune responses directed against maternal HIV-infected cells or free virus-bearing maternal major histocompatibility complex (MHC) determinants can account for protection of some children (38). Evidence that anti-MHC immune responses can protect against HIV-1 infection comes from a macaque model in which immunization with a human lymphoblastoid cell line protected macaques against subsequent simian immunodeficiency virus challenge when the challenge virus was grown in the same cell line (39). Protection in this model correlated best with antibodies against HLA class I molecules (40). In humans, this hypothesis is supported by a recent study showing that HLA class I antigen concordance between a mother and her child is associated with an increased risk of intrauterine HIV-1 transmission, whereas maternalchild HLA discordance results in protection against transmission (30).

\section{Chemokine Receptors and Ligands}

The search for other HIV receptors in addition to CD4 has permitted the identification of chemokine receptors as coreceptors for HIV cellular entry (reviewed in 41,42$)$. The CCR5 chemokine receptor that selectively binds $\beta$-chemokines such as RANTES, MIP-1 $\alpha$, and MIP-1 $\beta$, appears to be the main coreceptor for macrophage-tropic or nonsyncytium-inducing (NSI) HIV-1 strains, whereas the T-cell-tropic or syncytium-inducing strains preferentially use the SDF1 chemokine receptor, CXCR4. Some HIV-1 isolates are dual tropic and can use both CCR5 and CXCR4 receptors. A limited proportion of strains can also use additional chemokine receptors, such as CCR2 and CCR3.

\section{Polymorphism of CCR5}

Three independent groups have identified a mutant allele containing a 32 base pair (bp) deletion in the open reading frame of the CCR5 gene (CCR5- $\triangle 32$ ) that induces a frame shift, a premature stop codon, and loss of a HIV-1 coreceptor activity (43-45). The frequency of this mutant allele is approximately $1 \%$ in the homozygous state and $10-20 \%$ for the heterozygous state among North Americans and Europeans, but is lower or absent in subjects of African, Asian, and Latin American heritages (46). The CCR5- $\Delta 32$ allele has been identified as natural genetic polymorphism reducing the risk of acquiring HIV-1 infection and the rate of disease progression in high risk adults such as homosexuals, intravenous drug users, and hemophiliacs (reviewed in 31,47$)$. The complete absence of CCR5 expression in CCR $5-\Delta 32$ homozygotes is strongly protective against infection by macrophage-tropic HIV-1 
Table 3. Summary of published reports on the association between heterozygosity for CCR5- $\Delta 32$ chemokine receptor allele and the risk of MTCT of HIV-1 or the rate of disease progression

\begin{tabular}{|c|c|c|c|c|}
\hline \multirow[b]{2}{*}{ Population } & \multirow[b]{2}{*}{ (n) Patients } & \multicolumn{2}{|c|}{ Risk Factor } & \multirow[b]{2}{*}{ Reference } \\
\hline & & Risk of MTCT & Rate of HIV progression & \\
\hline African American & 144 & None & None & 52 \\
\hline Argentinean & 886 & None & None & 28,53 \\
\hline Austrian & 79 & $\downarrow$ & NS & 20 \\
\hline French & 512 & None & $\downarrow$ & 25 \\
\hline Mixed American & 122 & None & NS & 54 \\
\hline Mixed American & 831 & None & NS & 55 \\
\hline Mixed American & 457 & NS & $\downarrow$ & 26 \\
\hline Mixed American & 41 & NS & $\downarrow$ & 27 \\
\hline Spaniard & 73 & None & None & 38 \\
\hline
\end{tabular}

NS, not studied; $\downarrow$, decreased.

strains and infected heterozygotes progress more slowly to AIDS and death, compared to those bearing two functional CCR5 alleles. Heterozygosity for the $\Delta 32$ allele has been associated with some reduction in heterosexual transmission in one study (48) but other groups $(49,50)$ have not been able to confirm this observation. Recent studies have demonstrated that most vertical transmission occurs with macrophage-tropic or NSI viral isolates $(15,51)$ and that progression to AIDS occurs more rapidly in infants with NSI strains (14), suggesting that the polymorphism of CCR5 might influence pediatric HIV-1 infection. The role of CCR $5-\Delta 32$ allele in perinatal HIV-1 transmission and subsequent disease progression has recently been examined in over 3000 infants from different populations $(20,25-28,52-55)$. Table 3 summarizes the results of published reports on the association between CCR $5-\Delta 32$ chemokine receptor allele in children and the risk of vertical transmission of HIV-1 or disease progression. Taken together, these data suggest that CCR $5-\Delta 32$ heterozygosity alone is not protective against MTCT of HIV-1. Moreover, the protective effect of CCR5- $\Delta 32$ homozygosity observed in adult HIV-1 transmission was not conclusively demonstrated in vertical transmission, presumably because the total number of homozygote children found in these studies was too low. A larger number of mother-child pairs is thus required to determine the true impact of CCR $5-\Delta 32$ homozygosity in MTCT.

Although most studies have shown that CCR5$\Delta 32$ heterozygosity has no effect on MTCT of HIV-1, the role of this polymorphism in pediatric HIV disease progression remains a controversial issue. Reduced rates of disease progression have been observed in mixed American and French cohorts, although no effects were found in other cohorts composed mainly of Hispanic and African-American children (see Table 3). The mechanism of the protective effect of the $\Delta 32$ mutation is still unknown, but it is tempting to speculate that reduced expression of the CCR5 coreceptor at the cell surface may be associated with decreased efficiency of HIV-1 NSI strains entry and replication in CD4 T cells.

Other genetic polymorphisms have been identified within the CCR5 regulatory region, some of which have been reported to affect the rate of HIV disease progression in adults (56-58). A recent study in a mixed American population of 1442 infants has demonstrated that homozygosity for CCR5-59356-T allele is strongly associated with a higher rate of vertical transmission of HIV-1 among black infants (21).

\section{Polymorphism of CCR2}

Adults who possess the CCR2-64I allele (isoleucine substitution for valine at position 64) are not protected against HIV-1 infection, but progress less rapidly to disease once infected $(56,58,59-61)$. This protective effect is more pronounced among Africans than non-Africans. The fact that CCR2 is a sporadic coreceptor for HIV-1 macrophage-tropic strains and that CCR2-64I does not affect CCR2 protein expression makes it difficult to explain the protective effect observed in adults. However, CCR2-64I is in linkage disequilibrium with CCR5-59653T polymorphism located in the CCR5 promoter region (61). It has been suggested that CCR2-64I could interfere with CCR5 coreceptor expression, but this hypothesis was rejected by a recent in vitro study showing that the CCR2-64I allele does not influence CCR5 transcription or mRNA levels (62). Another possibility 
is that CCR2-64I does not act directly but simply reflects the association of other linked polymorphisms in the CCR5 promoter region that influence AIDS pathogenesis. However, unlike CCR5-59356T, the CCR2-64I allele was not associated with MTCT in African and non-African children $(28,63)$. The CCR2-64I allele has been associated with a delay in AIDS progression in the Argentineans (28), but this finding was not confirmed in French and African HIV-1-infected children (63).

\section{Polymorphism of SDF1}

A genetic polymorphism in the untranslated region of the SDFl gene (SDF1-3'A) has been associated with delayed progression to AIDS in homozygous adults from some cohorts (64). However, in other cohorts, the same homozygous genotypes had either no effect (58) or were associated with accelerated progression to death $(56,65)$. In children exposed to HIV-1 perinatally, the infant SDF1 genotype does not appear to have any effect on MTCT $(22,28)$ or disease progression (28). However, an increased risk of vertical transmission of HIV-1 has been associated with maternal SDF1-3'A heterozygosity (22). This association was observed mainly with postnatal breast milk transmission in a cohort of motherinfant pairs in Nairobi, Kenya.

\section{Conclusion and Future Directions}

A growing body of literature implicates HLA and chemokine receptor genes as key determinants of both perinatal transmission of HIV-1 and subsequent disease progression among children. However, major discrepancies have been observed between studies that may reflect the genetic heterogeneity of both the virus and the host, as well as the intrinsic clinical variations of HIV disease itself. Furthermore, the specific factors that influence the mechanism of transmission may be different depending on the time at which transmission occurs. For instance, HIV-1 transmission in utero may take place by a process that is more dependent on HLA molecules than chemokine receptor expressions, compared with transmission that occurs at or after birth. As a result, pediatric HIV infection displays the characteristics of a complex trait; that is, many variables can work independently or in concert to modulate the clinical phenotype. Such complexity is the major barrier to dissection of the molecular bases of such traits. Future studies should focus on restricted and clear phenotypes (e.g., in utero HIV-1 transmission) in well-characterized, homogeneous, and large epidemiologic samples in different populations. This strategy will significantly reduce several of the confounding factors that impede genetic association studies such as phenotypic heterogeneity in the definition of the cases, differences in the genetic backgrounds of cases and controls, lack of assessment of other risk factors, and small sample size (66). As the complete anatomy of the human genome is now before us $(67,68)$, we are rapidly advancing upon the postgenomic era, in which detailed genetic information will allow us to determine risk profiles for a wide range of diseases. Moreover, the identification of such genetic factors in HIV disease will undoubtedly enhance our understanding of the pathogenesis of this infection and may lead to the development of novel therapies and interventions.

\section{Acknowledgments}

This work was supported in part by grant \# PG-50917 from the Elizabeth Glaser Pediatric AIDS Foundation. M.R. is supported by a career award from Fonds de la Recherche en Santé du Québec (FRSQ).

\section{References}

1. UNAIDS. (2000) Report on the global HIV/AIDS epidemic, June 2000. Available from URL: http://www.unaids.org/ epidemic_update/report/index.html.

2. Kaul R, Makadzange T, Rowland-Jones S. (2000) AIDS in Africa: a disaster no longer waiting to happen. Nat. Immunol. 1: 267-270.

3. Khun L, Stein ZA. (1995) Mother-to-infant HIV transmission: timing, risk factors and prevention. Paediatr. Perinat. Epidemiol. 9: 1-29.

4. Mofenson LM. (1997). Mother-child HIV-1 transmission. Obstet. Gynecol. Clin. North Am. 24: 759-785.

5. Zorrilla CD. (1997). Obstetric factors and mother-to-infant transmission of HIV-1. Infect. Dis. Clin. North Am. 11: 109-118.

6. Hermione Lyall EG, Tudor-Williams G. (1997). Perinatal transmission of HIV. Curr. Opin. Infect. Dis. 10: 239-245.

7. Blanche S, Mayaux MJ, Rouzioux C, et al. (1994). Relation of the course of HIV infection in children to the severity of the disease in their mothers at delivery. N. Engl. J. Med. 330: 308-312.

8. Vigano A, Balotta C, Trabattoni D, et al. (1996). Virologic and immunologic markers of disease progression in pediatric HIV infection. AIDS Res. Hum. Retroviruses 12: 1255-1262.

9. Andiman W. (1999). Association between the biological characteristics of HIV-1, vertical transmission of infection and clinical progression of pediatric disease. Curr. Opin. Infect. Dis. 12: 239-244.

10. Mayaux MJ, Burgard M, Teglas JP, et al. (1996). Neonatal characteristics in rapidly progressive perinatal acquired HIV-1 disease. JAMA 275: 606-610.

11. Kuhn L, Steketee RW, Weedon J, et al. (1999). Distinct risk factors for intrauterine and intrapartum human immunodeficiency virus transmission and consequences for disease progression in infected children. J. Infect. Dis. 179: 52-58.

12. Shearer WT, Quinn T, LaRussa P, et al. (1997). Viral load and disease progression in infants infected with human immunodeficiency virus type 1. N. Engl. J. Med. 336: 1337-1342.

13. Dickover RE, Dillon M, Leung KM, et al. (1998). Early prognostic indicators in primary perinatal human immunodeficiency virus type 1 infection: Importance of viral RNA and the timing of transmission on long-term outcome. J. Infect. Dis. 178: $375-387$.

14. Spencer LT, Ogino MT, Dankner WM, Spector SA. (1994). Clinical significance of human immunodeficiency virus type 1 phenotypes in infected children. J. Infect. Dis. 169: 491495.

15. DeRossi A, Ometto L, Maserio S, Zanchetta M, Chieco-Bianchi L. (1997). Viral phenotype in mother-to-child HIV-1 transmission and disease progression of vertically acquired HIV-1 infection. Acta Paediatrica 421: 22-28.

16. Mark TW, Simard JJL. (1998). Handbook of immune responses genes. New York: Plenum.

17. Kilpatrick DC, Hague RA, Yap PL, Mok JY. (1991) HLA antigen frequencies in children born to HIV-infected mothers. Dis. Markers 9: 21-26. 
18. Winchester R, Chen Y, Rose S, Selby J, Borkowsky W. (1995). Major histocompatibility complex class II DR alleles DRB $1^{*} 1501$ and those encoding HLA-DR 13 are preferentially associated with a diminution in maternally transmitted human immunodeficiency virus 1 infection in different ethnic groups: determination by an automated sequence-based typing method. Proc. Natl. Acad. Sci. U.S.A. 92: 12374-12378.

19. Just JJ, Abrams E, Louie LG, et al. (1995). Influence of host genotype on progression to acquired immunodeficiency syndrome among children infected with human immunodeficiency virus type 1. J. Pediatr. 127: 544-549.

20. Mandl CW, Aberle SW, Henkel J, Puchhammer-Stockl E, Heinz FX. (1998). Possible influence of mutant CCR5 allele on vertical transmission of HIV-1. J. Med. Virol. 55: 51-55.

21. Kostrikis LG, Neumann AU, Thomson B, et al. (1999). A polymorphism in the regulatory region of the CC-chemokine receptor 5 gene influences perinatal transmission of human immunodeficiency virus typel to African-American infants. J. Virol. 73: 10264-10271.

22. John GC, Rousseau CM, Dong T, et al. (2000) Maternal SDF13'A polymorphism is associated with increased perinatal human immunodeficiency virus type 1 transmission. J. Virol. 74: 5736-5739.

23. Chen Y, Winchester R, Korber B, et al. (1997). Influence of HLA alleles on the rate of progression of vertically transmitted HIV infection in children: Association of several HLA-DR 13 alleles with long-term survivorship and the potential association of HLA-A*2301 with rapid progression to AIDS. Hum. Immunol. 55: 154-162.

24. Just JJ, Casabona J, Bertran J, et al. (1996). MHC class II alleles associated with clinical and immunological manifestations of HIV-1 infection among children in Catalonia, Spain. Tissue Antigens 47: 313-318.

25. Misrahi M, Teglas JP, N'Go N, et al. (1998). CCR5 chemokine receptor variant in HIV-1 mother-to-child transmission and disease progression in children. JAMA 279: 277-280.

26. Barroga CF, Raskino C, Fangon MC, et al. (2000). The CCR5 del 32 allele slows disease progression of human immunodeficiency virus-1-infected children receiving antiretroviral treatment. J. Infect. Dis. 182: 413-419.

27. Bakshi SS, Zhang L, Ho DD, Than S, Pahwa SG. (1998). Distribution of CCR5 del 32 in human immunodeficiency virusinfected children and its relationship to disease course. Clin. Diagn. Lab. Immunol. 5: 38-40.

28. Mangano A, Kopka J, Batalla M, Bologna R, Sen L. (2000). Protective effect of CCR2-64I and not of CCR5-del 32 and SDF1-3'A in pediatric HIV-1 infection. J. Acquir. Immune Defic. Syndr. 23: 52-57.

29. Townsend A, Bodmer H. (1989) Antigen recognition by class I-restricted T lymphocytes. Annu. Rev. Immunol. 7: 601-624.

30. MacDonald KS, Embree J, Njenga S, et al. (1998). Motherchild class I HLA concordance increases perinatal human immunodeficiency virus type 1 transmission. J. Infect. Dis. 177: $551-556$.

31. Roger M. (1998). Influence of host genes on HIV-1 disease progression. FASEB J. 12: 625-632.

32. Ogg GS, Jin X, Bonhoeffer S, et al. (1998). Quantitation of HIV-1-specific cytotoxic T lymphocytes and plasma load of viral RNA. Science 279: 2103-2 106.

33. Jin X, Roberts CGP, Nixon DF, et al. (1998). Longitudinal and cross-sectional analysis of cytotoxic $\mathrm{T}$ lymphocyte responses and their relationship to vertical human immunodeficiency virus transmission. J. Infect. Dis. 178: 1317-1326.

34. DeMaria A, Cirillo C, Moretta L. (1994). Occurrence of human immunodeficiency virus type 1 specific cytolylic $\mathrm{T}$ cell activity in apparently uninfected children born to HIV-1 infected mothers. J. Infect. Dis. 170: 1296-1299.

35. Wilson CC, Brown RC, Korber B, et al. (1999). Frequent detection of escape from cytotoxic $\mathrm{T}$ lymphocyte recognition in perinatal human immunodeficiency virus type 1 transmission: the Ariel project for prevention of transmission of HIV from mother to infant. J. Virol. 73: 3975-3985.
36. Lewis SH, Reynolds-Kohler C, Fox HE, Nelson JA. (1990). HIV-1 in trophoblastic and villous Hofbauer cells, and haematological precursors in eight-week fetuses. Lancet 335: 565-568.

37. Kesson AM, Fear WR, Kazazi F, et al. (1993). Human Immunodeficiency Virus typel infection of human placental macrophages in vitro. J. Infect. Dis. 168: 571-579.

38. Mittleman BB, Shearer GM. (1996). Mother-to-infant transmission of HIV type 1: Role of Major Histocompatibility Antigen Differences. AIDS Res. Hum. Retroviruses 12: 13971400 .

39. Stott EJ, Chan WL, Mills KH, et al. (1990). Preliminary report: Protection of cynomolgus macaques against simian immunodeficiency virus by fixed infected-cell vaccine. Lancet 336: 1538-1541.

40. Chan WL, Rodgers A, Hancok RD, et al. (1992). Protection in simian immunodeficiency virus vaccinated monkeys correlates with anti-HLA class I antibody response. J. Exp. Med. 176: 1203-1207.

41. Gallo RC, Lusso P. (1997). Chemokines and HIV infection. Curr. Opin. Infect. Dis. 10: 12-17.

42. Cairns JS, D'Souza MP. (1998). Chemokines and HIV-1 second receptors: the therapeutic connection. Nat. Med. 4: 563-568.

43. Dean M, Carrington MN, Winkler C, et al. (1996). Genetic restriction of HIV-1 infection and progression to AIDS by a deletion allele of the CKR5 structural gene. Science 273: 1856-1862.

44. Samson M, Libert F, Doranz BJ, et al. (1996). Resistance to HIV-1 infection in Caucasian individuals bearing mutant alleles of the CCR-5 chemokine receptor gene. Nature 382: 722-725.

45. Liu R, Paxton WA, Choe S, et al. (1996). Homozygous defect in HIV-1 coreceptor accounts for resistance of some multiplyexposed individuals to HIV-1 infection. Cell 86: 367-377.

46. Martinson JJ, Chapman NH, Rees DC, Liu YT, Clegg JB. (1997). Global distribution of the CCR5 gene 32-basepair deletion. Nat. Genet. 16: 100-103.

47. McNicholl JM, Smith DK, Qari SH, Hodge T. (1997). Host genes and HIV: The role of the chemokine receptor gene CCR5 and its allele (del 32 CCR5). Emerging Infect. Dis. 3: 261-271.

48. Hoffman TL, MacGregor RR, Burger H, Mick R, Doms RW, Collman RG. (1997). CCR5 genotypes in sexually active couples discordant for human immunodeficiency virus type 1 infection status. J. Infect. Dis. 176: 1093-1096.

49. O'Brien TR, Padian NS, Hodge T, Goedert JJ, O'Brien SJ, Carrington M. (1998). CCR-5 genotype and sexual transmission of HIV-1. AIDS 12: 444-445.

50. Lockett SF, Alonso A, Wyld R, et al. (1999). Effect of chemokine receptor mutations on heterosexual human immunodeficiency virus transmission. J. Infect. Dis. 180: 614-620.

51. Ometto L, Zanotto C, Maccabruni A, et al. (1995). Viral phenotype and host-cell susceptibility to HIV-1 infection as risk factors for mother-to child HIV-1 transmission. AIDS 9: 427-434.

52. Rousseau CM, Just JJ, Abrams EJ, Casabona J, Stein Z, King MC. (1997). CCR5 del 32 in perinatal HIV-1 infection. J. Acquir. Immune Defic. Syndr. Hum. Retrovirol. 16: 239-242.

53. Mangano A, Prada F, Roldan A, Picchio G, Sen L. (1998). Distribution of CCR-5 del 32 allele in Argentinean children at risk of HIV-1 infection: its role in vertical transmission. AIDS 12: 109-123.

54. Edelstein RE, Manns Arcuino LA, Hughes JP, et al. (1997). Risk of mother-to-infant transmission of HIV-l is not reduced in CCR5/del 32 CCR5 heterozygotes. J. Acquir. Immune Defic. Syndr. Hum. Retrovirol. 16: 243-246.

55. Shearer WT, Kalish LA, Zimmerman PA. (1998). CCR5 HIV-l vertical transmission. J. Acquir. Immune Defic. Syndr. Hum. Retrovirol. 17: 180-181.

56. Mummidi S, Ahuja SS, Gonzalez E, et al. (1998). Genealogy of the CCR5 locus and chemokine system gene variants associated with altered rates of HIV-1 disease progression. Nat. Med. 4: 786-793. 
57. Martin MP, Dean M, Smith MW, et al. (1998). Genetic acceleration of AIDS progression by a promoter variant of CCR5. Science 282: 1907-1911.

58. Easterbrook PJ, Rostron T, Ives N, Troop M, Gazzard BG, Rowland-Jones S. (1999). Chemokine receptor polymorphisms and human immunodeficiency virus disease progression. J. Infect. Dis. 180: 1096-1105.

59. Smith MW, Dean M, Carrington M, et al. (1997). Contrasting genetic influence of CCR 2 and CCR 5 variants on HIV-1 infection and disease progression. Science 277: 959-965.

60. Anzala AO, Ball TB, Rostron T, et al. (1998). CCR2-64I allele and genotype association with delayed AIDS progression in African women. Lancet 351: 1632-1633.

61. Kostrikis LG, Huang Y, Moore JP, et al. (1998). A chemokine receptor CCR2 allele delays HIV-1 disease progression and is associated with a CCR5 promotor mutation. Nat. Med. 4: 350-353.

62. Mariani R, Wong S, Mulder LCF, et al. (1999). CCR2-64I polymorphism is not associated with altered CCR5 expression or coreceptor function. J. Virol. 73: 2450-2459.
63. Teglas JP, N'Go N, Burgard M, et al. (1999). CCR2B-64I chemokine receptor allele and mother-to-child HIV-1 transmission or disease in children. French pediatric HIV infection study group. J. Acquir. Immune Defic. Syndr. 22: 267-271.

64. Winkler C, Modi W, Smith MW, et al. (1998). Genetic restriction of AIDS pathogenesis by an SDF-1 chemokine gene variant. Science 279: 389-393.

65. Brambilla A, Villa C, Rizzardi G, et al. (2000). Shorter survival of SDF1-3'A/3'A homozygotes linked to CD4 T Cell decreased in advanced human immunodeficiency virus type 1 infection. J. Infect. Dis. 182: 311-315.

66. Gambaro G, Anglani F, D'Angelo A. (2000). Association studies of genetic polymorphisms and complex disease. Lancet 355: 308-311.

67. Venter JC, Adams MD, Myers EW, et al. (2001). The sequence of the human genome. Science 291: 1304-1351.

68. International Human Genome Sequencing Consortium. (2001). Initial sequencing and analysis of human genome. Nature 409: 860-921. 